\title{
Naranja de Acridina, obtención de Bacillus thuringiensis H-14 var. israelensis mutante y producción de bioinsecticida por fermentación con sanguaza.
}

\author{
Orange acridine for obtaining Bacillus thuringiensis $\mathrm{H}-14$ var. \\ israelensis mutant and bioinsecticide production by fermentative sanguaza.

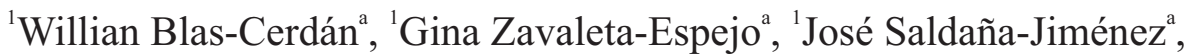 \\ ${ }^{2}$ Juan Pedro-Huamán,${ }^{1}$ Pedro Lezama-Ascencio ${ }^{a}$ y ${ }^{1}$ Lurdes Tuesta-Collantes ${ }^{a}$.
}

\section{RESUMEN}

El objetivo general es evaluar el efecto del naranja de acridina en la obtención de Bacillus thuringiensis H-14 var. israelensis mutante y la producción de bioinsecticida en un medio fermentativo a base de sanguaza. Se utilizó un testigo y cuatro concentraciones del mutágeno con 80 ppm, 120 ppm, 160 ppm, y 200 ppm, las colonias mutantes se seleccionaron en base a sus características fenotípicas comparadas con el grupo testigo. La producción de biomasa se realizó en biorreactores tipo tanque cilíndrico aireado y agitado, las fermentaciones se llevaron a cabo por 50 horas a temperatura ambiente $\left(20 \pm 1^{\circ} \mathrm{C}\right), \mathrm{pH}$ inicial de 7,0 y un inóculo microbiano de $10^{9} \mathrm{UFC}$. La biomasa se estimó por recuento en placa, obteniéndose el máximo valor a las 40 horas en cada uno de los tratamientos, con mutantes obtenidos a diferentes concentraciones de naranja de acridina ( $15,7 \times 10^{9}$ UFC), excepto en el testigo. Se determinó que la producción de bioinsecticida se incrementa en proporción directa con respecto a las concentraciones del mutágeno, ocurriendo la máxima producción con 200 ppm., la que se cuantificó en gramos de peso seco por litro $(2.78 \mathrm{~g} / \mathrm{L})$; no existiendo relación directa entre el crecimiento exponencial de la biomasa y la producción del bioinsecticida.

Palabras clave: naranja de acridina, mutante, bioinsecticida, sanguaza, Bacillus thuringiensis.

\section{ABSTRACT}

The main objetive was to evaluate the effect of acridine orange for obtaining Bacillus thuringiensis H-14 var. israelensis mutant and a bioinsecticide production by fermentation of sanguaza. A control and four mutagen concentrations at $80 \mathrm{ppm}, 120 \mathrm{ppm}, 160 \mathrm{ppm}$ and $200 \mathrm{ppm}$. were used. The mutants colonies were select based on their phenotypic characteristics compare to the control group. The biomass production was made in aired cylindrical and stirring bioreactors, the fermentations were carried out during 50 hours at room temperature $\left(20 \pm 1^{\circ} \mathrm{C}\right)$, initial $\mathrm{pH}$ of 7,0 and microbial inoculum of $10^{9}$ UFC. The biomass was estimated by the recount method in plate, obtaining the maximum concentrations at 40 hours in each of the orange acridine treatments $\left(15,7 \times 10^{9} \mathrm{UFC}\right)$, except in the check It was determined that bioinsecticide production increased in direct proportion with respect to the mutagen concentrations. The maximum production at $200 \mathrm{ppm}$, was counted in dry weight grams per liter $(2.78 \mathrm{~g} / \mathrm{L})$. It's not demonstration direct relation between exponential growth biomass and bioinsecticide production.

Keywords. acridine orange, mutant, bioinsecticide, sanguaza, Bacillus thuringiensis.

\footnotetext{
'Universidad Nacional de Trujillo. Trujillo, Perú.

${ }^{2}$ Universidad Nacional de Jaén. Cajamarca, Perú. 


\section{INTRODUCCIÓN}

Las plagas de insectos en zonas urbanas y rurales, se han convertido en una amenaza constante para la salud y calidad de vida del hombre, ocasionando también, pérdidas económicas en cultivos agrícolas; representando entre el $10 \%$ y $30 \%$ de los costos de producción, hasta ahora la única forma eficaz de controlar los insectos plaga se basa en la aplicación de pesticidas químicos, y su uso irracional ha sido la principal causa de contaminación ambiental. Con el surgimiento de los plaguicidas de origen órgano-sintéticos se ha disminuido la biodiversidad, e inducido resistencia en este tipo de insectos, provocando un desequilibrio del balance ecológico. Se conoce aproximadamente 500 especies de insectos resistentes a uno o más agroquímicos y el número pueden aumentar considerablemente en pocos años (Baddi, Flores y Quiroz 1996, 40-47; Galán et al. 1996, 139152).

Los productos biológicos a base de Bacillus thuringiensis $(B t)$, son de mayor difusión y uso a nivel internacional por su alta especificidad, inocuidad para el hombre, animales y plantas, al no dejar residuos tóxicos en el ambiente; ya se han identificado una gran cantidad de cepas $B t$ con diferentes rangos de acción insecticida, la mayoría tiene actividad contra lepidópteros pero también se ha encontrado cepas nocivas para dípteros, coleópteros, ácaros, platelmintos y nemátodos (Longini 2000).

B. thuringiensis es una bacteria que se encuentra en la flora natural del suelo, de forma bacilar, Gram positiva, anaeróbica facultativa $\mathrm{y}$ formadora de esporas; esta bacteria produce toxinas altamente específicas contra insectos, cuya producción comercial se realiza por fermentación en grandes biorreactores (Jian, Thirumaran y Porter 1996). Después se propaga en una fase vegetativa y exponencial; cuando un compuesto nutritivo del medio se agota, la bacteria entra en fase de esporulación sintetizando las proteínas toxigénicas en forma de cristales (Cranshaw 2007).

Determinados agentes ambientales, físicos o químicos pueden alterar la estructura molecular del ADN de $B t$, provocando una mayor frecuencia de mutaciones, a los mismos que se les denomina mutágenos o agentes mutagénicos. Dentro de los mutagénicos químicos se encuentran el 5-Bromouracilo, etil metano sulfonato (EMS), ácido nitroso, cloruro de hidroxilamina, naranja de acridina, entre otros, pudiéndose agruparse en varias categorías como: análogo de bases, hidroxílantes, desaminantes, alquilantes e intercalares (Polo 1999).

Naranja de acridina, es un colorante catiónico selectivo de los ácidos nucleicos y se encuentra dentro de los agentes mutagénicos intercalares, integrándose entre las bases nitrogenadas del ADN, originando delecciones o inserciones de un solo par de nucleótidos. Por lo común ocasiona un desenrrollamiento parcial del ADN, inhibiendo la transcripción (Griffiths et al. 2008, 487-513).

Debido a la importancia de $B$. thuringiensis $\mathrm{H}$ 14 var. israelensis (Bti) en la producción de bioinsecticida, cuyos genes se encuentran muy emparentados entre sí, así como el efecto genotóxico del naranja de acridina, y al no existir trabajos relacionados en nuestro país; se ha creído conveniente desarrollar una nueva estrategia que permita incrementar la producción del bioinsecticida por Bti mutante en un medio fermentativo a base de sanguaza, con la finalidad de identificar las diferentes concentraciones del naranja de acridina en la consecución de colonias de Bti mutante y determinar la máxima producción de bioinsecticida según la concentración del agente mutágeno y establecer la relación entre la producción de biomasa y la producción de bioinsecticida. 


\section{MATERIALES Y MÉTODOS}

Material Biológico: Cepa de Bacillus thuringiensis $\mathrm{H}-14$ var. israelensis (Bti), donada por el Instituto de Medicina Tropical Alexander Von Humboltd de la Universidad Peruana Cayetano Heredia; perteneciente al lote $\mathrm{N}^{\mathrm{o}}$ 91509 del Instituto Pasteur de París-Francia. Sanguaza, obtenida del Terminal Pesquero de Buenos Aires (Provincia de Trujillo Departamento La Libertad); la misma que fue conservada en congelación a $-20^{\circ} \mathrm{C}$ (Díaz 2003).

\section{Agente Mutagénico}

Se utilizó "naranja de acridina" (tetrametilacridina), compuesto orgánico cuya fórmula química es 1-7 (dimetil) (9-amino) antraceno; con un peso molecular de $265 \mathrm{~g} / \mathrm{mol}$.

\section{Métodos y técnicas}

\section{Reactivación y aislamiento de la cepa}

El liofilizado de Bti fue homogenizado en un medio líquido de agar Triptosa Fosfato (TPH) incubándose a $30^{\circ} \mathrm{C}$ por 4 horas (Zavaleta 2010). Cumplido el tiempo de incubación se tomó una alícuota del cultivo obtenido en el medio TPH y se sembró por el método de agotamiento en agar Nysma para la esporulación (Ventocilla 2001); a $30{ }^{\circ} \mathrm{C}$ por 24 horas (Parry, Turnbull y Gibson 1988).

\section{Determinación de la dosis letal media $\left(\mathrm{DL}_{50}\right)$ y dosis letal máxima $\left(\mathrm{DL}_{100}\right)$}

Se pesaron $5,10,20,40$ y $80 \mathrm{mg}$ del naranja de acridina y se diluyeron en $100 \mathrm{~mL}$ de medio Nysma, obteniendo concentraciones de 50 ppm, 100 ppm, 200 ppm, 400 ppm y 800 ppm; posteriormente se procedió a la siembra de $B t i$, tomando $0,1 \mathrm{~mL}$ de suspensión a una concentración equivalente al tubo $\mathrm{N}^{\circ} 4$ del Nefelómetro de MacFarland (1,2 x $10^{9}$ $\mathrm{UFC} / \mathrm{mL}$ ). La dosis media y la dosis letal máxima se determinó a través del recuento de colonias de la bacteria con respecto a las diferentes concentraciones del mutágeno a partir de estas se eligieron las concentraciones en el experimento.

\section{Diseño de exposición del Bti al mutágeno}

Se eligieron cinco concentraciones del naranja de acridina incluyendo al testigo: $0 \mathrm{ppm}, 80 \mathrm{ppm}$, 120 ppm, 160 ppm y 200 ppm, luego se procedió a realizar la siembra en placa a $30^{\circ} \mathrm{C}$ por 48 horas, siguiendo un diseño experimental completamente aleatorizado, donde cada concentración es un tratamiento y cada tratamiento se repitió tres veces.

\section{Selección de mutantes}

Los mutantes de Bti se detectaron mediante la comparación de las características fenotípicas de las colonias mutante en relación al testigo. Se escogieron aquellas con mayor diámetro de crecimiento en cada repetición dentro de cada tratamiento.

\section{Diseño de los Biorreactores}

Se diseñaron y construyeron tres biorreactores tipo tanque cilíndrico aireado agitado (TCAA) de dos litros de capacidad, con un volumen de trabajo de 1,4 L y flujos de aire de $0,5 \mathrm{vvm}$ a 220 rpm de agitación. Para ello se emplearon frascos de vidrio, con tapas herméticas acondicionadas con orificios de salida de $\mathrm{CO}_{2}$; la entrada de aire se realizó por la parte inferior de las paredes del frasco, y se colocaron caños para la toma de las muestras. Los biorreactores fueron esterilizados con luz UV por media hora, y el aire insuflado se esterilizó por burbujeo en una solución de $\mathrm{NaCl}$ al $30 \%$.

\section{Preparación del medio fermentativo a base de sanguaza}

Para la obtención del bioinsecticida se tomó como referencia un medio de producción a gran escala (Abarca et al. 1992), adicionando sanguaza, previamente diluida al décimo, en reemplazo de la fuente nitrogenada, el medio 
fermentativo se esterilizó en autoclave a $121^{\circ} \mathrm{C} /$ 15 min. a 1 atm. de presión.

\section{Estandarización del inóculo}

Se obtuvo una suspensión densa de Bti mutante en solución salina fisiológica al 0,9\% para cada tratamiento, a partir de ellas se hicieron diluciones hasta obtener una concentración de $10^{9}$ UFC/mL (Pescorán 1998).

Inoculación de Bti mutante en los biorreactores

Se agregó $170 \mathrm{~mL}$ de la suspensión bacteriana estándar a cada uno de los biorreactores conteniendo $1230 \mathrm{~mL}$ de medio fermentativo, según los tratamientos considerados, la inoculación se llevó a cabo en agitación y aireación constante con un $\mathrm{pH} 7.0$ a temperatura ambiente $\left(20 \pm 1^{\circ} \mathrm{C}\right)$.

Control de la producción y evaluación del bioinsecticida

E1 bioproceso duró 50 horas, durante la fermentación se realizaron muestreos cada 10 horas, incluyendo el tiempo cero, extrayendo 5 $\mathrm{mL}$ de medio fermentativo para evaluar $\mathrm{pH}$, temperatura, recuento de células vegetativas y células esporulantes por el método de recuento en placa. Se realizaron coloraciones con verde de malaquita modificado para el control microbiológico (Parry, Turnbull y Gibson 1988).

\section{Obtención del boinsecticida}

Una vez terminado el tiempo de fermentación, se centrifugó el medio fermentativo de los diferentes biorreactores a $3500 \mathrm{rpm}$ por 15 minutos, eliminándose el sobrenadante. El precipitado se deshidrató a $60{ }^{\circ} \mathrm{C}$ por 24 horas (Parry, Turnbull y Gibson 1988), la biomasa seca fue triturada y pesada. Se considera como formulación insecticida al contenido total de esporas, cristales proteicos y residuos celulares, cuantificándose en gramos de peso seco por litro.

\section{Análisis Estadístico}

Con los datos obtenidos se realizaron los cálculos para estimar la línea de regresión, así como el análisis de varianza y la prueba de Duncan, para determinar la existencia de diferencias significativas entre los tratamientos con respecto al peso seco del bioinsecticida y las concentraciones del agente mutagénico (Sokal 1980, 510-612). Se utilizó el programa SPSS para determinar la curva de crecimiento logarítmico, con una $P E=0,05$.

\section{RESULTADOS}

Se obtuvo colonias de Bacillus thuringiensis $\mathrm{H}-$ 14 var. israelensis (Bti) mutante a partir de una concentración de naranja de acridina a 80 ppm, las mismas que se pueden identificar por el fenotipo que presentan con respecto a las colonias testigo (figura 1 ).

En la figura 2, se compara el crecimiento en relación al número y tamaño de las colonias mutantes de Bti en un medio Nysma para la esporulación, con diferentes concentraciones del mutágeno a las 48 horas de exposición, en relación con un testigo.

En la tabla 1, se muestra las unidades formadoras de colonias mutante de Bti expuestas a diferentes concentraciones del naranja de acridina, en un medio a base de sanguaza a las 50 horas de fermentación; obteniéndose los máximos valores de 40 horas en cada uno de los tratamientos ( 80 ppm: 14,8; 120 ppm: 15,4; 160 ppm: 15,7 y 200 ppm; $14,6 \times 10^{9} \mathrm{UFC} / \mathrm{mL}$ ), excepto en el testigo.

La producción promedio en peso seco del bioinsecticida del Bti mutante obtenida a diferentes concentraciones del naranja de acridina (ppm) en un medio a base de sanguaza a las 50 horas de fermentación, estuvo incrementada en relación directa a las concentraciones del mutágeno, ocurriendo la máxima producción a $200 \mathrm{ppm}(2.78 \mathrm{~g} / \mathrm{L})($ Tabla 2). 
El análisis de varianza, para la producción promedio del bioinsecticida de Bti mutante obtenida a diferentes concentraciones del naranja de acridina en un medio a base de sanguaza a 50 horas de fermentación, mostró diferencias significativas entre los tratamientos (Tabla 3).

En la tabla 4, se observa que mediante la Prueba de Comparación de Promedios de Duncan, las concentraciones del 0 ppm, $80 \mathrm{ppm}$ y $120 \mathrm{ppm}$ presentan diferencias significativas con las concentraciones de 160 ppm y 200 ppm del naranja de acridina, respecto a la producción promedio del bioinsecticida Bti.
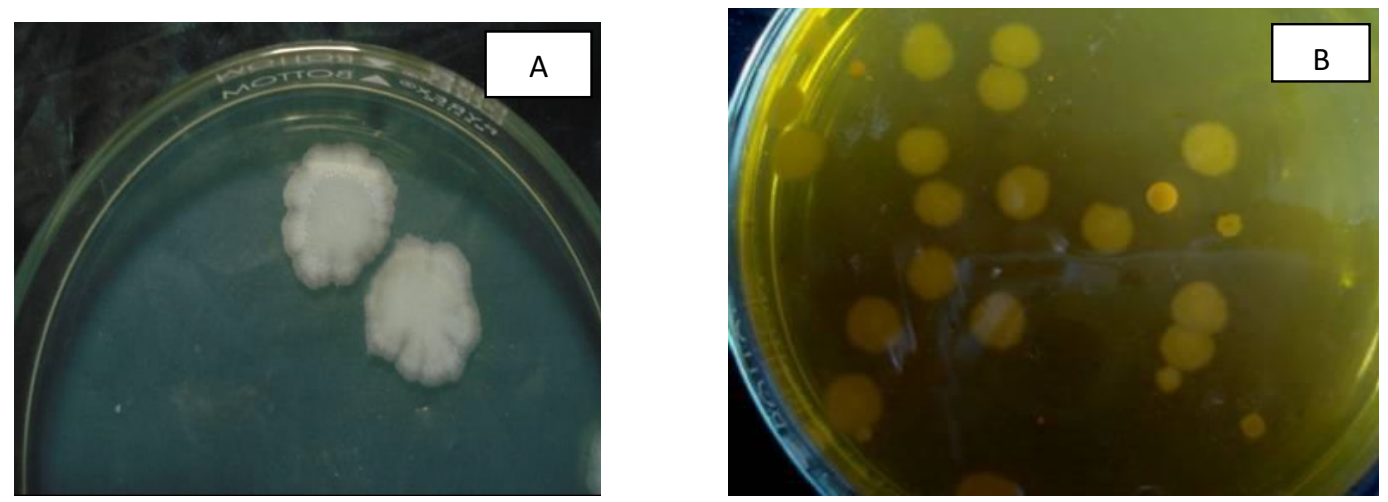

Figura 1. Colonias de Bacillus thuringiensis H-14 var. israelensis a las 48 horas después de la siembra.

\section{A: Testigo, B: Expuestas al agente mutagénico}
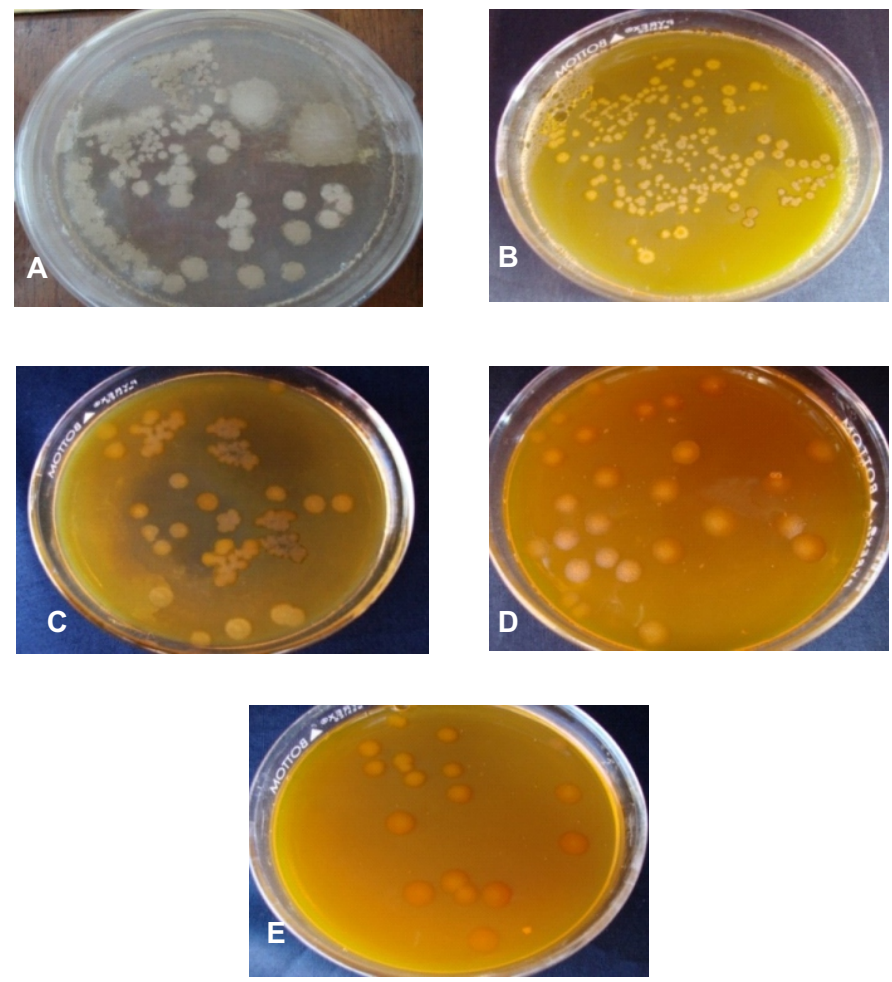

Figura 2. Crecimiento en relación al número y tamaño de colonias de Bacillus thuringiensis $\mathrm{H}-14$ var. israelensis a diferentes concentraciones del naranja de acridina a las 48 horas de exposición A: 0 ppm, B: 80 ppm, C: 120 ppm, D: 160 ppm y E: 200 ppm 
Tabla 1. Unidades formadoras de colonias de Bacillus thuringiensis $\mathrm{H}-14$ var. israelensis (UFC/mL) obtenidas a diferentes concentraciones de naranja de acridina (ppm) en un medio fermentativo a base de sanguaza a las 50 horas de fermentación.

\begin{tabular}{|c|c|c|c|c|c|}
\hline \multirow{2}{*}{$\begin{array}{c}\text { TIEMPO } \\
\text { (horas) }\end{array}$} & \multicolumn{5}{|c|}{ TRATAMIENTOS } \\
\hline & $\begin{array}{r}T_{1} \\
(0 \mathrm{ppm})\end{array}$ & $\begin{array}{c}T_{2} \\
(80 \text { ppm) }\end{array}$ & $\begin{array}{c}T_{3} \\
(120 \mathrm{ppm})\end{array}$ & $\begin{array}{c}T_{4} \\
(160 \mathrm{ppm})\end{array}$ & $\begin{array}{c}T_{5} \\
(200 \text { ppm) }\end{array}$ \\
\hline $\mathbf{0}$ & 10,15 & 7,08 & 6,75 & 6,62 & 6,32 \\
\hline 10 & 10,42 & 9,77 & 10,50 & 9,49 & 9,86 \\
\hline 20 & 10,24 & 8,58 & 9,83 & 10,60 & 10,70 \\
\hline 30 & 10,10 & 12,70 & 13,30 & 13,20 & 13,40 \\
\hline 40 & 9,74 & 14,80 & 15,40 & 15,70 & 14,60 \\
\hline 50 & 9,80 & 9,78 & 10,60 & 9,70 & 10,00 \\
\hline
\end{tabular}

Temperatura ambiente $20 \pm 1^{\circ} \mathrm{C}$

Tabla 2. Producción promedio del bioinsecticida $(\mathrm{g} / \mathrm{L})$ por Bacillus thuringiensis H-14 var. israelensis obtenida a diferentes concentraciones de naranja de acridina (ppm) en un medio fermentativo a base a sanguaza a las 50 horas de fermentación.

\begin{tabular}{cccccc}
\hline & \multicolumn{5}{c}{ T R A T A M I E N T O S } \\
\cline { 2 - 6 } REPETICIONES & $\mathbf{T}_{\mathbf{1}}$ & $\mathbf{T}_{\mathbf{2}}$ & $\mathbf{T}_{\mathbf{3}}$ & $\mathbf{T}_{\mathbf{4}}$ & $\mathbf{T}_{\mathbf{5}}$ \\
& $\mathbf{( 0 \mathbf { ~ p p m } )}$ & $\mathbf{( 8 0} \mathbf{~ p p m})$ & $\mathbf{( 1 2 0} \mathbf{~ p p m})$ & $(\mathbf{1 6 0} \mathbf{~ p p m})$ & $(\mathbf{2 0 0} \mathbf{~ p p m})$ \\
\hline $\mathbf{R}_{\mathbf{1}}$ & 1,89 & 8,00 & 2,15 & 2,49 & 2,95 \\
$\mathbf{R}_{\mathbf{2}}$ & 1,72 & 1,78 & 2,00 & 2,74 & 2,64 \\
$\mathbf{R}_{3}$ & 1,70 & 1,83 & 2,10 & 2,36 & 2,75 \\
\hline Promedio & $\mathbf{1 , 7 7}$ & $\mathbf{1 , 8 4}$ & $\mathbf{2 , 0 8}$ & $\mathbf{2 , 5 3}$ & $\mathbf{2 , 7 8}$
\end{tabular}

Tabla 3. Análisis de varianza para la producción promedio del bioinsecticida $(\mathrm{g} / \mathrm{L})$ por Bacillus thuringiensis H-14 var. israelensis obtenida a diferentes concentraciones de naranja de acridina (ppm) en un medio fermentativo a base a sanguaza a las 50 horas de fermentación.

\begin{tabular}{cccccc}
\hline $\begin{array}{c}\text { Fuente de } \\
\text { Variación }\end{array}$ & $\begin{array}{c}\text { Grados de } \\
\text { Libertad }\end{array}$ & $\begin{array}{c}\text { Suma de } \\
\text { Cuadrados }\end{array}$ & $\begin{array}{c}\text { Cuadrado } \\
\text { Medio }\end{array}$ & F- calculado & F- tabulado \\
\hline $\begin{array}{c}\text { Entre } \\
\text { tratamientos } \\
\begin{array}{c}\text { Dentro de } \\
\text { tratamientos }\end{array}\end{array}$ & 4 & 2,33 & 0,583 & 97,16 & $3,48^{*}$ \\
\hline Total & 10 & 0,06 & 0,006 & & \\
\hline * Presentan diferencias significativas & P.E.: 0,05
\end{tabular}

Tabla 4. Prueba de comparación de medias de Duncan para la producción promedio del bioinsecticida $(\mathrm{g} / \mathrm{L})$ por Bacillus thuringiensis $\mathrm{H}-14$ var. israelensis obtenida a diferentes concentraciones de naranja de acridina (ppm) en un medio fermentativo a base a sanguaza a las 50 horas de fermentación.

\begin{tabular}{|c|c|c|}
\hline Tratamientos & $\begin{array}{l}\text { Promedio de } \\
\text { Bioinsecticida }\end{array}$ & Grupos Homogéneos \\
\hline$T_{5}:(20 \%)$ & 2,78 & $\mathbf{x}$ \\
\hline$T_{4}:(16 \%)$ & 2,53 & $\mathbf{x}$ \\
\hline$T_{3}:(12 \%)$ & 2,08 & $\mathbf{x}$ \\
\hline$T_{2}:(8 \%)$ & 1,84 & $\mathbf{x}$ \\
\hline $\mathrm{T}_{1}:(0 \%)$ & 1,77 & $\mathbf{x}$ \\
\hline
\end{tabular}

\section{DISCUSIÓN}

Se consiguió obtener colonias mutantes de Bti a diferentes concentraciones del mutágeno naranja de acridina, las colonias se observan como estructuras de bordes rugosos, con superficies lisas, compactas y sobresalientes, de color blanco cremoso y de centro brillante en el testigo. Transcurridas 48 horas de exposición al agente mutágeno, las características morfológicas de las colonias mutantes muestran bordes regulares, superficies lisas, opacas y uniformes, de color anaranjado cremoso pero más pequeñas que las colonias testigo (figura 1). Estos cambios se deberían a la acción del mutágeno naranja de acridina, que produce alteraciones de tipo intercalar en la molécula del ADN, dando origen a la ganancia o pérdida de nucleótidos; generando un desplazamiento en el marco de lectura del mensaje genético, ocasionando cambios en el genotipo, los mismos que se traducen en el fenotipo; cuya aplicación en concentraciones variables ha permitido la obtención de mutantes bacterianos para diferentes propósitos (Griffiths et al. 2008, 487513). Resultados similares fueron descritos por López-Camacho, quienes trabajaron con cloruro de hidroxilamina en Bacillus subtilis y $B$. licheniformis, citados por (Polo 1999).

El número de las colonias de Bti mutante presentan una relación inversamente proporcional a las concentraciones del agente mutágeno (figura 2), pues el naranja de acridina provoca un desenrrollamiento parcial en la estructura molecular del ADN, inhibiendo la transcripción y la traducción ocasionando la 
muerte celular, de tal manera que sobreviven solo las bacterias que han logrado superar esta dificultad (Griffiths et al. 2008, 487-513). En la misma figura se aprecia que el crecimiento de las colonias de Bti mutante se incrementaron a medida que las concentraciones del mutágeno aumentan, lo cual se hizo más notorio en los tratamientos con 160 ppm y 200 ppm; posiblemente que al existir menor número de colonias mutantes mayor sería la velocidad de crecimiento. La explicación de estos fenómenos se fundamenta en que las mutaciones pueden causar daños en el ADN de manera reversible, debido a los mecanismos de reparación que han desarrollado a lo largo de su proceso evolutivo, acelerando su capacidad de adaptación ante factores adversos, aunado a la falta de competencia por el sustrato, tal como se describe en (Klug y Cummings 1999, 411-452).

El número promedio de colonias de Bti mutante en su fase logarítmica alcanza su valor más alto a las 40 horas del bioproceso en todos los tratamientos con el agente mutagénico, con excepción del testigo que lo hace en las primeras 10 horas. Este crecimiento lento, se debería a las diferentes concentraciones del naranja de acridina y a los mecanismos de repación del $\mathrm{ADN}$ en la bacteria, ocasionando alteraciones en su metabolismo, siendo su valor máximo de 15,7 x $10^{9} \mathrm{UFC} / \mathrm{mL}$, a $160 \mathrm{ppm}$ del agente mutagénico y a las 40 horas de fermentación (tabla 1); coincidiendo con los resultados obtenidos por Razo en 1990, en escalamiento de un proceso a nivel de laboratorio a planta piloto para la producción de Bt; y Abarca et al. 1992, en estudios de optimización de procesos fermentativos para producir $B t$ de la variedad aisawai; quienes encontraron una producción final de 10,08 x $10^{9}$ y 5,5 × $10^{9} \mathrm{UFC} / \mathrm{mL}$ respectivamente entre las 24 y 50 horas de fermentación; valores muy bajos a lo conseguido por (Gil 2009), quien reporta $5,4 \times 10^{15}$ $\mathrm{UFC} / \mathrm{mL}$, en una investigación utilizando almidón como fuente carbonada en un medio de fermentación durante 48 horas; esto se explicaría porque $B t$ presenta la enzima amilasa que hidroliza al almidón hasta glucosa, esencial fuente de energía para el crecimiento aeróbico. Zavaleta en el 2010, obtuvo una producción de $10^{11} \mathrm{UFC} / \mathrm{mL}$ en la evaluación de la capacidad biocida de Bti cultivado en sanguaza sobre larvas de Aedes aegypti.

La máxima producción del bioinsecticida de $B t i$ mutante al final del bioproceso se logró a una concentración de $200 \mathrm{ppm}$ de naranja de acridina, con un peso seco promedio de $2,78 \mathrm{~g} / \mathrm{L}$ (tabla 2). Este resultado es mayor al conseguido por Abarca et al quien halló una producción final de 1,78 y $1,40 \mathrm{~g} / \mathrm{L}$ de peso seco entre 24 y 48 horas de fermentación; sin embargo estos valores pueden incrementarse después de las 56 horas. Los resultados conseguidos en el presente trabajo se encuentran por debajo de la producción del bioinsecticida de Bti obtenida por (Gil 2009), quien reporta 3,33 g/L de peso seco promedio. Por lo tanto, se puede establecer que no existe relación entre el crecimiento en su fase exponencial y la producción del bioinsecticida Bti mutante, por lo que se puede afirmar que hay una asincronía en el proceso de esporulación, alargándose según las diferentes concentraciones del mutágeno.

Los resultados distintos en la producción del bioinsecticida de Bti mutante indicado con sus promedios fueron confirmados por el análisis de varianza (tabla 3 ), para identificar la existencia de diferencias significativa entre los tratamientos; sin embargo, a pesar de ser un método riguroso, es muy genérico y sensible a las diferencias que puedan presentar por lo menos un par de tratamientos; ante ello se hizo necesario aplicar un método más específico, la prueba de comparación de promedios de Duncan (tabla 4), para determinar entre que tratamientos existen tales diferencias (Sokal 1980, 510-612). 
Es necesario precisar que el proceso de fermentación de Bti se lleva a cabo en condiciones óptimas a un $\mathrm{pH}$ de 7,0 y a una temperatura de $30^{\circ} \mathrm{C}$ (De Urquijo 1987); y nuestro bioproceso ocurrió a un $\mathrm{pH}$ inicial de 7,0, disminuyendo a partir de las 35 horas hasta llegar a un valor de 5,0 a las 50 horas; más aún cuando se trabajó a temperatura ambiente de $20 \pm 1^{\circ} \mathrm{C}$.

La producción del bioinsecticida por Bacillus thuringiensis H-14 var. israelensis (Bti), requiere de un medio adecuado para el crecimiento, esporulación y la formación de la $\delta$ - endotoxina, además de conocer los requerimientos nutricionales principalmente de carbono y nitrógeno (Robles y Lora 1998). En la presente investigación se pretende mejorar la producción del bioinsecticida por $B t i$, por ello se consideró emplear colonias mutantes de la bacteria obtenidas a diferentes concentraciones del mutágeno naranja de acridina; así como reemplazar la fuente nitrogenada por sanguaza en el medio fermentativo, según lo recomendado por Díaz en el 2003.

Para la producción de la proteína biocida de $B t i$ se hace necesario formular un medio de cultivo óptimo, pues de ello depende la calidad tóxica del cristal, de tal forma que las fuentes nutricionales y minerales deben mantener un balance para estimular una buena producción del bioinsecticida, como lo establece Galán et al en 1996. En relación a las fuentes nitrogenadas se ha reportado que el Bti requiere de aminoácidos esenciales y otras formas orgánicas de nitrógeno durante su fase de crecimiento y esporulación (Robles y Lora 1998). Sarama y Norris en 1993, lograron conseguir buena producción del bioinsecticida $B t i$, empleando sustancias de bajo costo tales como las proteínas de semilla cocida de algodón, soya, garbanzo, haba, maní, lenteja, sangre de res, suero de queso, productos de desechos de la industria láctea y de harina de pescado, de esta última se obtiene la sanguaza.
Existen otras variables que se deben considerar en la producción del bioinsecticida $B t i$, como son la velocidad de agitación y el suministro de oxígeno, para evitar la acumulación de calor e inhibición o reducción de la calidad de la proteína biocida (Galán et al 1996). Vásquez en el 2000, reportó un recuento de células de $B t$ de $10^{6} \mathrm{UFC} / \mathrm{mL}$ a las 48 horas de fermentación, esto se debería a la utilización de biorreactores con deficiencias de aireación; concordante con Bach en 1985, quien sugiere que la fuente de aireación en el medio es esencial para la esporulación; y la ausencia o disminución de oxígeno solo produce un crecimiento vegetativo. Por 10 antes mencionado se utilizó un biorreactor tipo tanque cilíndrico aireado y agitado, que permite una alta transferencia de oxígeno y en consecuencia un crecimiento ideal de Bti en el medio fermentativo (Gil 2009).

Es importante indicar, que la producción alcanzada del bioinsecticida de Bti mutante en esta investigación en relación a otros trabajos antes descritos, se basa en su capacidad biocida contra ciertos insectos plaga; y para ello se debe realizar ensayos "in vitro" e "in vivo" a nivel de laboratorio y campo respectivamente, esperando que su actividad tóxica resulte ser directamente proporcional a la producción.

\section{CONCLUSIONES}

Las colonias de Bacillus thuringiensis $\mathrm{H}-14$ var. israelensis (Bti) mutante se obtuvieron utilizando naranja de acridina a partir de una concentración de 80 ppm.

La producción máxima del bioinsecticida mutante Bti se logró a una concentración de 200 ppm del mutágeno a las 50 horas del bioproceso.

No existe una relación directa entre el crecimiento exponencial de la biomasa y la producción del bioinsecticida $B t i$.

\section{AGRADECIMIENTOS}

A la Universidad Nacional de Jaén por la oportunidad que nos brinda para poder difundir esta investigación. 


\section{REFERENCIAS BIBLIOGRÁFICAS}

Abarca, C., A. Martínez, M. Caro y R. Quintero. 1992. Optimización del proceso de fermentación para producir Bacillus thuringiensis var. Aisawai. Universidad: Ciencia y Tecnología.

Bach, P. 1985. Control biológico de plagas de insectos y malas hierbas. Cuernavaca-México, Continental, S.A: 21-89 p.

Baddi, M., A. Flores y R. Quiroz. 1996. Ecología de manejo integrado de plagas. MonterreyMéxico, Universidad Autónoma de Nuevo León: 40-47.p

Cranshaw, W. 2007. Questions and answers about Bacillus thuringiensis. Colorado State University Cooperative Extension. http://searchpdf.adobe.com/proxies/1/26/81/4.h tml. (Consultado el 21 de Octubre del 2013).

De Urquijo, G. 1987. Producción de Bacillus thuringiensis para el control de ciertas plagas de importancia agrícola. Tesis de Maestría, CINVESTAV-IPN. 34-75p.

Díaz, F. 2003. Influencia de la sanguaza y aireación sobre algunos parámetros cinéticos de Bacillus thuringiensis durante la producción de Bioinsecticida en biorreactor Airlift. Tesis para optar el grado de Maestro en Biotecnología y Bioingeniería, Universidad Nacional de Trujillo.45-72p.

Galán, L., J. García, Z. Quintero y H. Luna. 1996. Producción de Bacillus thuringiensis: Avances en la Biotecnología. Monterrey-México, Universidad Autónoma de Nuevo León: 139152.p

Gil, B. 2009. Efecto de la fuente carbonada en la producción de bioinsecticida por Bacillus thuringiensis. Tesis para optar el Título de Biólogo - Microbiólogo. Universidad Nacional de Trujillo. 12-87p.

Griffiths, A., S. Wessler, R. Lewontin y S. Carroll. 2008. Genética. Madrid. España, McGraw Hill. ed: 487-513p.

Jian, L., Y. Thirumaran y A. Porter. 1996. Efficent
Síntesis of Mosquitocidal Toxins in ASticcacaulis excentricus Demonstrates Potential of Gram negative Bacteria in Mosquito Control. Nature Biotechnology; 14: 343-347p.

Klug, W. y M. Cummings. 1999. Conceptos de Genética. Madrid. España, Prince Hall: 411$452 p$.

Longini, M. 2000. El primer Bioinsecticida Argentino. http://www.biodiversidadla/agro. (Consultado el 22 de octubre del 2013).

Parry, M., P. Turnbull y J. Gibson. 1988. A colour Atlas of Bacillus Species. London, England: Edit Wolfe Medical Publications Ltd. 32-46p.

Pescorán, M. 1998. Efecto del pH y temperatura sobre la producción de bioinsecticida por Bacillus thuringiensis en un medio de cultivo suplementado con "sanguaza". Tesis para optar el título de Biólogo-Microbiólogo. Universidad Nacional de Trujillo. 15-72p.

Polo, E. 1999. Efecto del cloruro de hidroxilamina en la producción de queratinasas por Bacillus polymyxa MIT-LVI, utilizando como sustrato plumas de aves. Tesis para optar el grado de Maestro en Ciencias. Universidad Nacional de Trujillo-Perú. 16-77p.

Razo, F. 1990. Escalamiento de un proceso por lote de nivel de laboratorio a planta piloto para la producción de Bacillus thuringiensis. Tesis de Maestría. Instituto de investigaciones biomédicas. Departamento de Biotecnología.23-57p.

Robles, H. y C. Lora. 1998. Sanguaza y levadura residual en la producción de bioinsecticidas por Bacillus thuringiensis. Libro de resúmenes del I Congreso Peruano de Biotecnología y Bioingeniería. 72-78p.

Sarama, H. y O. Norris. 1993. The use of Bacillus thuringiensis in developing countries. New York: Jhon Wiley \& Sons Ltd.18-45p.

Sokal, R. 1980. Introducción a la Bioestadística. Barcelona-España, Edit. Reverté S.A: 510-612p.

Vásquez, C. 2000. Influencia de las concentraciones de almidón de papa en un medio 
fermentativo a base de sanguaza sobre la producción de bioinsecticida por Bacillus thuringiensis. Tesis para optar el título de Biólogo-Microbiólogo. T-1611. Universidad Nacional de Trujillo. 21-62p.

Ventocilla, P. 2001. Producción de Bacillus thuringiensis $\mathrm{H}-14$ var. israelensis usando alternativas locales para el control de vectores de enfermedades. Rivers of the World. 31-45p.

Zavaleta, G. 2010. Evaluación de la capacidad biocida de Bacillus thuringiensis H-14, var. Israelensis cultivado en sanguaza sobre larvas de Aedes aegypti en el distrito de Laredo, La Libertad-Perú. 2008-2009. Tesis para optar el grado de Doctor en Ciencias Biológicas. 15-43p.

\section{CORRESPONDENCIA}

Dr. Willian Genaro Blas Cerdan

Dirección: Calle Francisco Gonzales Burga $\mathrm{N}^{\circ}$ 944. Ferreñafe-Lambayeque.

Correo electrónico:wgbc_unt@hotmail.com 